\title{
LOCALIZACIÓN Y CARACTERIZACIÓN MORFOMÉTRICA DE LOS GLACIARES ROCOSOS RELICTOS DE LA SIERRA DE GISTREDO (MONTAÑA CANTÁBRICA, LEÓN)
}

\author{
J.M. REDONDO VEGA \\ A. GÓMEZ VILLAR \\ R.B. GONZÁLEZ GUTIÉRREZ \\ Dpto. Geografía, Facultad de Filosofía y Letras, \\ Universidad de León, Campus de Vegazana s/n. 24071-León \\ Correo electrónico de contacto: dgejrv@unileon.es
}

\begin{abstract}
RESUMEN: En la Sierra de Gistredo se han seleccionado 43 glaciares rocosos con el fin de estudiar los factores geoambientales (litología, exposición y altitud) que explican su distribución y diversos rasgos morfométricos significativos en función de su morfología (de lengua, lobulados y complejos). Los resultados confirman el rígido control que ejercen los factores geoambientales en su localización y en su forma. La aplicación de análisis estadísticos permite discriminar y caracterizar los tres tipos de glaciares rocosos atendiendo a su geometría y observar la escasa relación que existe entre su tamaño y pendiente y determinadas variables morfométricas referidas a su área fuente, como es la altitud, pendiente y desnivel.
\end{abstract}

ABSTRACT: 43 rockglaciers have been selected in the Gistredo range, in order to study the environmental factors (lithology, aspect, altitude) explaining their spatial distribution and several morphometric features according to morphology (tongue-shaped, lobate and complex forms). The results confirm the strong control to exert the environmental factors affecting both the location and their shape. The use of statistical analysis allow to discriminate and to clasify three types of rock glaciers according to geometry and to see the limited relations between the rockglaciers' surface and slope and some morphometric parameters of source-area (altitude, slope and altitudinal difference).

Palabras clave: Glaciares rocosos relictos, parámetros morfométricos, Sierra de Gistredo, Montaña Cantábrica, León.

Key words: Relict rock glaciers, morphometrical parameters, Gistredo Range, Cantabrian Mountains, León.

Enviado en Septiembre de 2004

Aceptado en Octubre de 2004 


\section{Introducción}

Los glaciares rocosos relictos o fósiles se han definido como glaciares rocosos antiguos que, presentando una morfología similar a la de los que son funcionales, tienen la particularidad de que todo el hielo que contenían en su momento (tanto si se trataba de lentejones de hielo internos, procedentes del glaciar que lo formó, como si se trataba de hielo intersticial y su origen estuvo en la dinámica periglaciar) se ha fundido caracterizándose, por este motivo, por la presencia de estructuras de colapso en superficie y por tener una topografía superficial mucho más suavizada que cuando eran funcionales (Barsch, 1996); otro rasgo distintivo es la cubierta vegetal, más o menos densa, que tapiza su superficie. Los términos relicto y fósil, se han utilizado indistintamente para referirse a aquellas formas resultantes de un glaciar rocoso que no contienen hielo en el presente. En nuestro caso los denominaremos relictos mejor que fósiles, para indicar que se trata de formas heredadas, de verdaderas herencias morfoclimáticas, para diferenciarlos de aquellos que sí presentan movimientos -glaciares rocosos activos-, así como de los que, aún no presentando movimientos, sí contienen hielo en su interior -glaciares rocosos inactivos-.

Los glaciares rocosos relictos constituyen una forma de modelado típico de alta montaña y son muy frecuentes en casi todas las cordilleras del mundo, lo que ha motivado la realización de numerosos estudios, dirigidos principalmente a la reconstrucción paleoambiental (Blagbrough \& Farkas, 1968; Zielinski, 1989; Frauenfelder \& Kääb, 2000) y a su localización, sedimentología, fábrica, cronología o génesis (Blagbrough, 1984; Barsch \& King, 1975; Sissons, 1976; Whalley, 1976; Dawson, 1977; Seret, 1983; Dzierzek \& Nitychoruk, 1986; Kotarba, 1988; Jong \& Kwadijk,1988; Schoeneich, 1992; Nicholas \& García, 1997; Borowicz \& Zurawek, 2003, entre otros).

En España, existen numerosos trabajos sobre morfologías periglaciares y manifestaciones heredadas de origen periglaciar en las montañas cantábricas, centrándose el mayor número de trabajos recientes en Picos de Europa (Castañón,1986; Alonso, 1989; Díaz Martínez, 1989; Frochoso, 1990; Castañón y Frochoso, 1994, entre otros), tal como recogen Gómez Ortiz et al. (2001). Los trabajos de Pérez Alberti et al. (1993a y 1993b), Valcárcel Díaz (1998) analizan el desarrollo espacial de modelados periglaciares en la montaña gallega. Respecto a la montaña leonesa, trabajos sobre localización y cartografía de glaciares rocosos se centran en la Montaña Occidental (García de Celis, 1991, 1997) y Montaña Central (González Gutiérrez, 2002). Por nuestra parte, a una primera descripción general de los glaciares relictos de un sector de la Cordillera Cantábrica (Redondo Vega et al., 1998), han seguido estudios preliminares sobre aspectos de fracturación de los macizos que alimentan los glaciares rocosos y sobre su fábrica (Redondo Vega et al., 2002a, 2002b).

En el estudio de los glaciares rocosos se han mantenido posturas divergentes sobre muchos aspectos que complican su interpretación, especialmente para los localizados en montañas deglaciadas, donde el permafrost está ausente y los glaciares rocosos relictos pueden ser interpretados erróneamente como morrenas o depósitos de deslizamiento 
(Matsuoka \& Ikeda, 1998). Esto es debido, tal como señalan estos autores (Ikeda \& Matsuoka, 2002), a que la morfología de los glaciares rocosos relictos no ha sido todavía definida de forma inequívoca, siendo, en este sentido, mucho menos numerosos aún los trabajos dedicados a la morfometría de glaciares rocosos relictos (Wilson, 1990).

La presencia de glaciares rocosos relictos, perfectamente conservados, en la Sierra de Gistredo (uno de los segmentos meridionales de la Cordillera Cantábrica), pone de manifiesto el hecho de haber estado sometida a unas condiciones paleoambientales de tipo periglaciar. La observación de fotogramas aéreos y ortofotos, complementada con trabajo de campo, nos ha permitido establecer diferentes morfologías y dimensiones de glaciares rocosos relictos, relacionados con una serie de factores topográficos, morfológicos y litoestructurales. El objetivo de este trabajo es analizar los principales rasgos de la distribución espacial de los glaciares rocosos, estudiar su diversidad morfométrica, atendiendo a su morfología, y jerarquizar los parámetros morfométricos más significativos.

\section{El área de estudio}

La Sierra de Gistredo constituye el conjunto de estribaciones montañosas que arman parte de la franja suroccidental de la Cordillera Cantábrica. Junto con la Sierra de Ancares, forma el cordón montañoso que cierra la fosa del Bierzo por el N; internamente, este conjunto, se encuentra organizado en numerosos cordales (Fig. 1) de dirección predominante ONO-ESE (alineaciones de Coto-Nevadín, en su extremo más septentrional, Valdeiglesia-Tambarón, Catoute, Vizbueno-Arcos del Agua y Gistredo, en su borde más meridional). La línea de cumbres supera los $1900 \mathrm{~m}$. de altitud, sobrepasando numerosas cimas los 2000 m. (Valdeiglesias, 2136 m., Tambarón, 2102 m., Catoute, 2112 m., etc.).

Todo el conjunto sirve de divisoria de aguas entre la cuenca del Duero, al Este, a través del río Omaña, y la cuenca del Miño, a través del Sil, que circula por su extremo occidental. El sistema de drenaje que avena el macizo dibuja una red radial, configurando una unidad homogénea, levantada frente a las fosas y cubetas adyacentes (Redondo Vega, 2002). La mayor parte de la red fluvial pertenece al sistema del Sil, caracterizándose por valles muy encajados, estrechos y con fuertes pendientes (ríos de Valseco, Salentinos, Primout, Noceda, Boeza, Tremor). En cambio, los tributarios que configuran la cabecera del río Omaña presentan perfiles transversales más abiertos y anchos, donde fondos más o menos llanos dan paso a laderas menos abruptas y escalonadas que terminan en cimas alomadas.

El área de estudio está constituida por materiales del Paleozoico inferior, que forman parte de la Zona Asturoccidental Leonesa, una de las grandes unidades en que se encuentra dividido el Macizo Hercínico Ibérico. Las capas más antiguas, del Cámbrico inferior, se agrupan en la fm Cándana (Fig. 2), caracterizándose por una sucesión detrítica de microconglomerados, areniscas, pizarras y cuarcitas tableadas blancas, cuya potencia llega a superar los $500 \mathrm{~m}$. A techo se sitúa una banda estrecha, la $\mathrm{fm}$ Vegadeo, de unos 
100-150 m., formada por mármoles, calizas marmóreas y dolomías masivas muy recristalizadas, pertenecientes al Cámbrico medio. Por encima se emplaza otro conjunto detrítico denominado la Serie de los Cabos, constituido por bancos de cuarcitas blancas que alternan con capas de areniscas y pizarras. Su potencia llega a superar los $7000 \mathrm{~m}$. y su edad es del Cámbrico superior y Ordovícico Inferior. El paso al siguiente gran conjunto sedimentario, las Pizarras de Luarca, se efectúa de forma gradual a través de una serie de transición, formada por una alternancia de pizarras y cuarcitas. La Serie de Luarca está constituida por pizarras negras masivas de grano fino del Ordovícico Medio, y su potencia supera los 1500 m. (Rodríguez Fernández \& Heredia, 1994).

La disposición estructural que presenta el macizo está relacionada con la Orogenia Hercínica, que deformó las series paleozoicas en sucesivas fases, formando unas estructuras que fueron fracturadas al final de la Orogenia por un sistema de fallas de dirección doble: NO-SE y NE-SO (Rodríguez Fernández, 1982a y 1982b). Todo este armazón estructural estuvo de nuevo afectado durante el Terciario por la Orogenia Alpina, responsable de la organización morfoestructural del macizo. Éste se levantó de forma generalizada, con respecto a la fosa del Bierzo y, en concreto, a la cubeta de Noceda. Internamente, todo el conjunto estuvo, además, afectado por el rejuego de las antiguas fallas y cabalgamiento paleozoicos, y de un nuevo sistema perpendicular al anterior. Esta tectónica de fractura es la que individualiza el macizo como tal, y la que organiza en gran parte la escorrentía hacia el valle del Sil y del Omaña respectivamente. Esta organización ha estado acompañada de la disección del macizo en numerosos cordales y de un profundo encajamiento, cuyas evidencias aún se plasman en los restos de superficies erosivas a diferentes niveles altitudinales (García de Celis, 1997).

El último retoque al relieve que actualmente se observa está relacionado con las huellas de formas de modelado de origen glaciar y periglaciar. La mayor parte de los valles albergaron durante el último episodio glaciar lenguas de hielo que partían desde los circos situados al pie de las cumbres y que confluían en los colectores principales, alcanzando cotas por debajo de los $900 \mathrm{~m}$. de altitud (Redondo Vega, 2002). A medida que las masas de hielo se retiraban, se fueron instalando unas condiciones morfoclimáticas periglaciares, que hicieron posible el desarrollo de glaciares rocosos.

\section{Métodos}

Mediante fotointerpretación (Vuelo Americano de 1956-57 a escala 1:33.000, vuelo del M.A.P.A. de 1990, a escala 1:20.000, y Ortofotos en color de la Junta de Castilla y León, de 2002, a escala 1:10.000), en el área de estudio se han seleccionado un total de 43 glaciares rocosos relictos, asentados sobre formas erosivas de origen glaciar y repartidos en cuatro alineaciones principales (Fig. 1), lo que significa una elevada concentración de este tipo de formas periglaciares, prácticamente única en todo el ámbito de la Cordillera Cantábrica.

En los 43 glaciares rocosos relictos seleccionados se han medido los siguientes parámetros: 


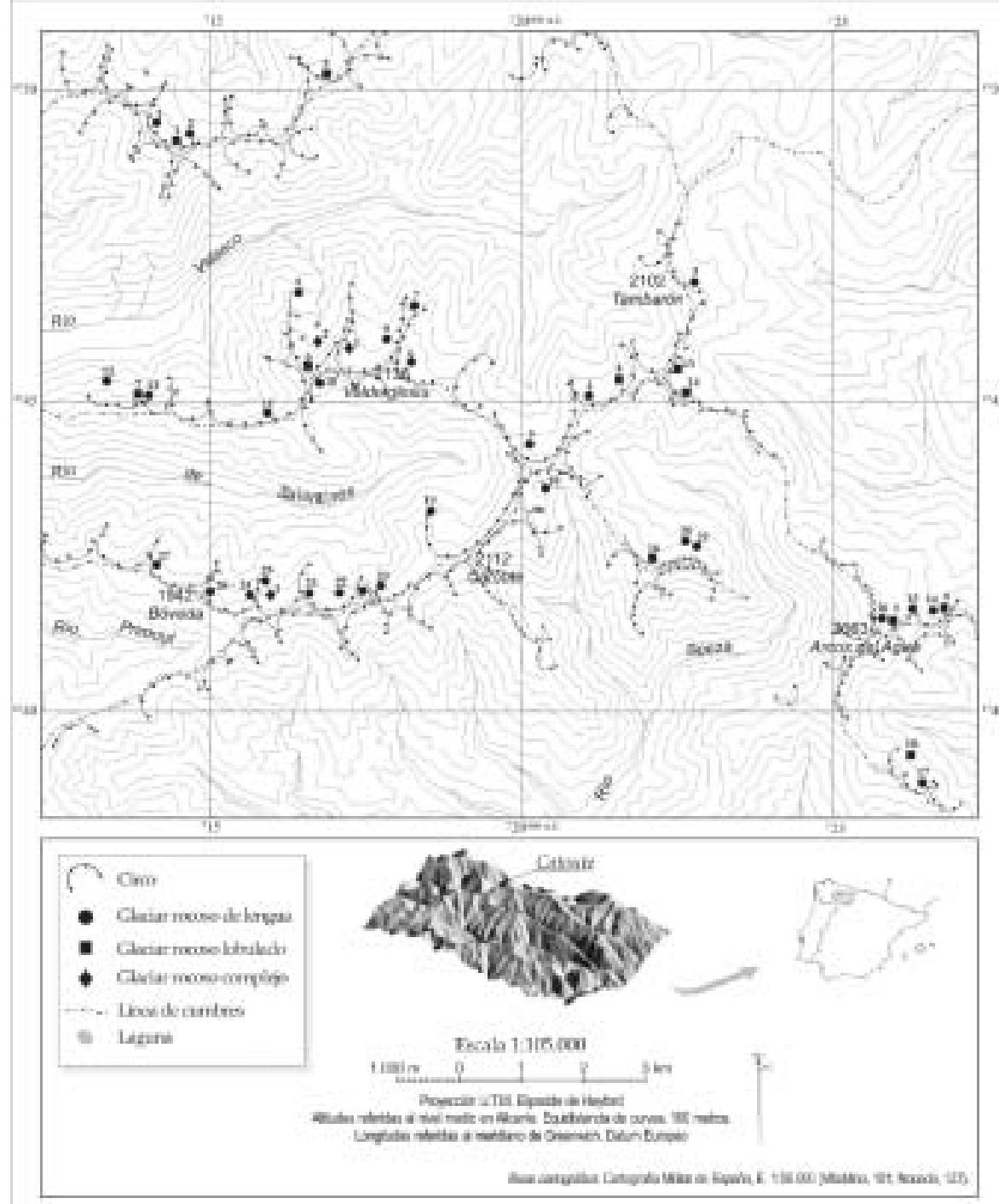

Figura 1. Localización de los glaciares rocosos en la Sierra de Gistredo.

- Longitud (L), en m, de la superficie del glaciar rocoso, medida en la dirección del flujo: La distancia máxima existente entre el punto medio de la zona de arranque del glaciar rocoso (raíz) y el punto medio del talud frontal.

- Anchura (A), en m: La distancia máxima entre los límites de la superficie del glaciar rocoso, tomada siguiendo la línea media transversal a la longitud. 


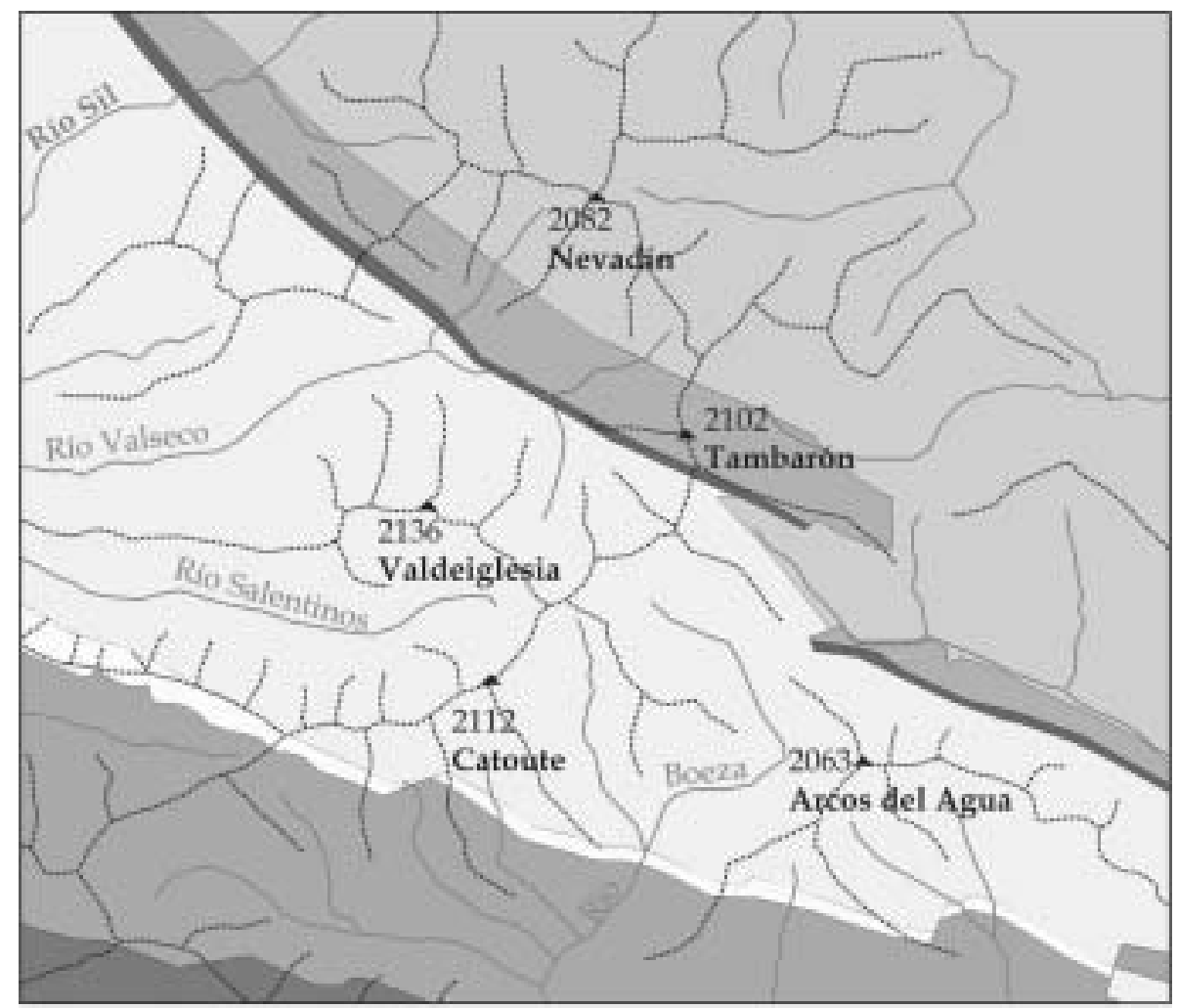

\section{LEYENDA}

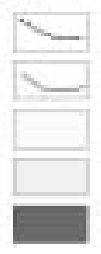

Coedales y divisonias prinsipules

Red flanial frincipal

Capes de Trasicikin

Seric de las Cubso

Fan Crabos de Vegaleu

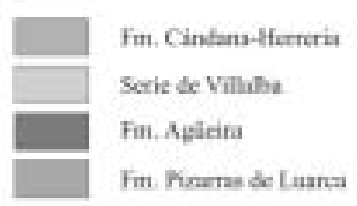

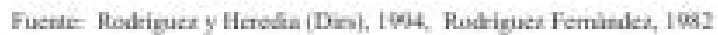

Figura 2. Esquema litológico del área de estudio.

- Altura de la raíz (Ar), en m: Corresponde a la altitud del punto medio donde arranca el glaciar rocoso, al pie del canchal.

- Altura del frente (Af), en m: Medida en el centro de la parte terminal de la superficie del glaciar rocoso.

- Exposición: Se han establecido seis categorías: (N, NNE, NE, NNW, NW y S). 
- Litología: No se han establecido categorías dado que prácticamente todos los glaciares rocosos están formados por cuarcitas del Paleozoico inferior.

Asimismo se incluyen datos de otras variables de los glaciares rocosos, derivadas de los parámetros morfométricos básicos anteriores, y del área-fuente:

- Superficie del glaciar rocoso (AGR), en $\mathrm{m}^{2}$.

- Desnivel del glaciar rocoso (Dgr). Diferencia, en m, entre la altura de la raíz y la altura del frente.

- Pendiente, en grados, del glaciar rocoso (PGR), en la línea media, desde la raíz al frente superficial.

- Relación entre la longitud y la anchura (L/A) de cada glaciar rocoso, que es un buen indicador de la forma en planta del glaciar rocoso, de su geometría.

- Altitud del área-fuente (Aaf), en m: Corresponde a la altitud máxima de la divisoria situada inmediatamente por encima del glaciar rocoso.

- Desnivel entre el área fuente y raíz del glaciar rocoso (Dafr), en m. Diferencia de altura entre la altitud del área fuente $(\mathrm{AaF})$ y la raíz (Ar) del glaciar rocoso.

- Pendiente, en grados, del área-fuente, tomada en la línea media desde la raíz a la divisoria.

Toda la información recogida ha sido almacenada, codificada y organizada en una base de datos para su tratamiento estadístico, el cual ha permitido realizar gráficos descriptivos básicos (tablas, histogramas de frecuencias, etc.) y aplicar distintos procedimientos de análisis estadísticos univariables y bivariables con el objetivo final de cuantificar los distintos parámetros y caracterizar morfometricamente los glaciares rocosos y discriminar los parámetros más significativos. En este sentido se han llevado a cabo medidas de centralización y dispersión, aplicadas especialmente para sintetizar los parámetros topográficos y morfométricos que definen a los glaciares rocosos y sus áreasfuente, tablas de frecuencias para explicar proporcionalmente la importancia relativa de cada categoría elegida, correlaciones entre las distintas variables morfométricas de los glaciares rocosos para obtener la medida del grado de asociación, así como otros procedimientos bivariables de contraste (anovas).

\section{Resultados}

\subsection{Distribución de los glaciares rocosos}

Morfológicamente, los glaciares rocosos relictos (Blagbrough, 1984; Haeberli, 1985) de la Sierra de Gistredo responden a las características básicas indicadas por varios autores (Wahrahfting \& Cox, 1959; Barsch, 1996) de manera que 29 de ellos tienen forma de lengua, 11 son lobulados (Fotos 1 y 2) y 3 los hemos denominado de carácter com- 
plejo (Foto 3). Si atendemos a su tipología (Barsch, 1992, 1996) la mayoría de ellos corresponden a los denominados talus rockglacier, asentados sobre formas erosivas de origen glaciar, con las raíces al pie de paredes muy escarpadas, cubiertas por canchales y los frentes por encima de cordales morrénicos. Los flancos laterales y el frente de los glaciares rocosos son muy empinados y en superficie muestran, transversal y longitudinalmente, una alternancia de surcos y crestas, éstas en ocasiones rotas, desorganizadas y/o redondeadas, con hundimientos y estructuras de colapso en determinados sectores. Los materiales en superficie son gruesos, angulosos, con diámetros que regularmente superan los $40 \mathrm{~cm}$ de diámetro, excepto en el ápice frontal de los glaciares rocosos de lengua, donde a menudo este sector está muy meteorizado y suavizado y predominan sedimentos de menor tamaño. Los glaciares rocosos lobulados tienen perfiles más suaves y llanos que los glaciares rocosos de lengua. Todos los glaciares rocosos están sometidos a distinto grado de colonización vegetal. Los materiales superficiales, excepto algunos bloques localizados en el fondo de los surcos, están colonizados por líquenes; a menudo, en los flancos laterales, frentes y sectores deprimidos, donde se localizan materiales más finos, crecen formaciones arbustivas (brecina, brezo, arándano, escobas) y en los estadios más avanzados aparecen especies arbóreas como avellanos, serbales y abedules (González Gutiérrez et al., 2004).

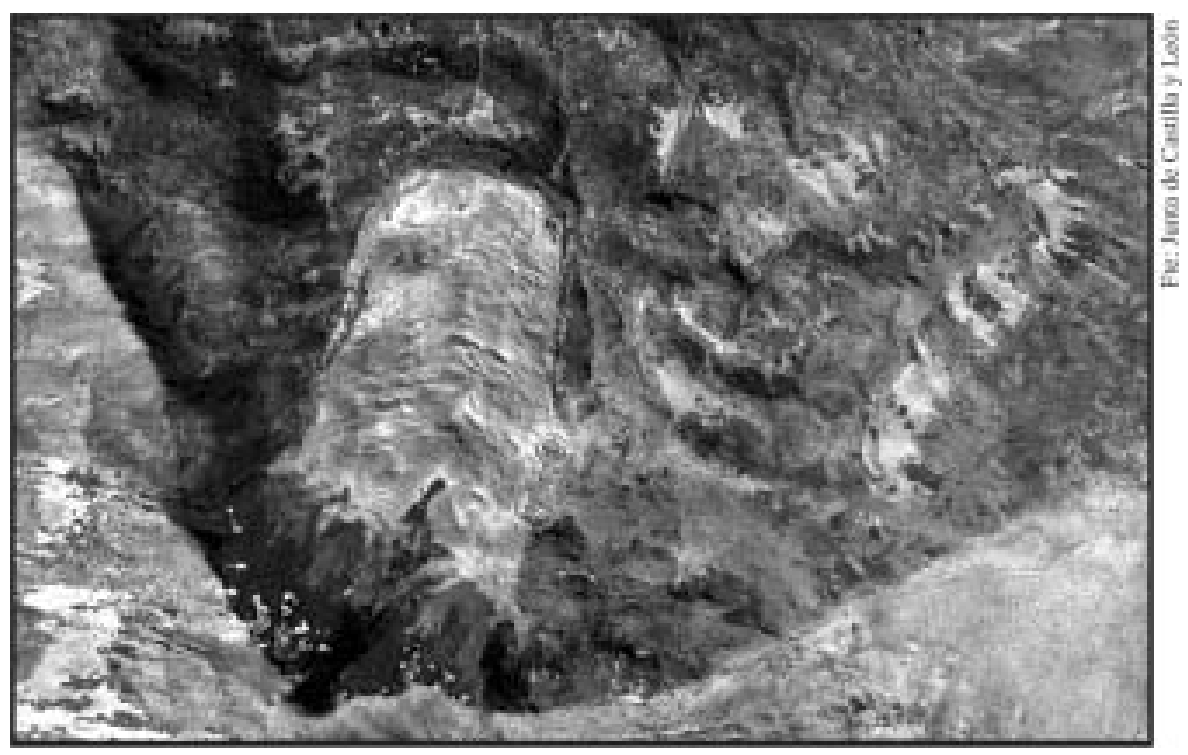

Foto 1. Glaciares rocosos situados en el circo de Brañalibrán.

Los glaciares rocosos se distribuyen aleatoriamente por los cuatro cordales principales que conforman la Sierra de Gistredo (Tabla 1): alineaciones de Coto-Nevadín, en su sector más septentrional (4 ejemplos), Valdeiglesia-Tambarón y Catoute, en la parte central, las cuales concentran el mayor número de glaciares rocosos (18 y14, respectiva- 
mente) a la vez que es el único sector donde se conservan glaciares rocosos de tipo complejo, y Vizbueno-Arcos del Agua (7 ejemplos), en las estribaciones más meridionales del área de estudio.

Tabla 1. Distribución de los tres tipos de glaciares rocosos en los cordales de la Sierra de Gistredo.

\begin{tabular}{|l|c|c|c|c|}
\cline { 2 - 5 } \multicolumn{1}{c|}{} & $\begin{array}{c}\text { Coto- } \\
\text { Nevadín }\end{array}$ & $\begin{array}{c}\text { Valdeiglesia- } \\
\text { Tambarón }\end{array}$ & Catoute & $\begin{array}{c}\text { Vizbueno- } \\
\text { Arcos del Agua }\end{array}$ \\
\hline G.R. de lengua & 2 & 10 & 13 & 5 \\
G.R. lobulado & 2 & 6 & 1 & 2 \\
G.R. complejo & 2 & 2 & \\
\hline
\end{tabular}

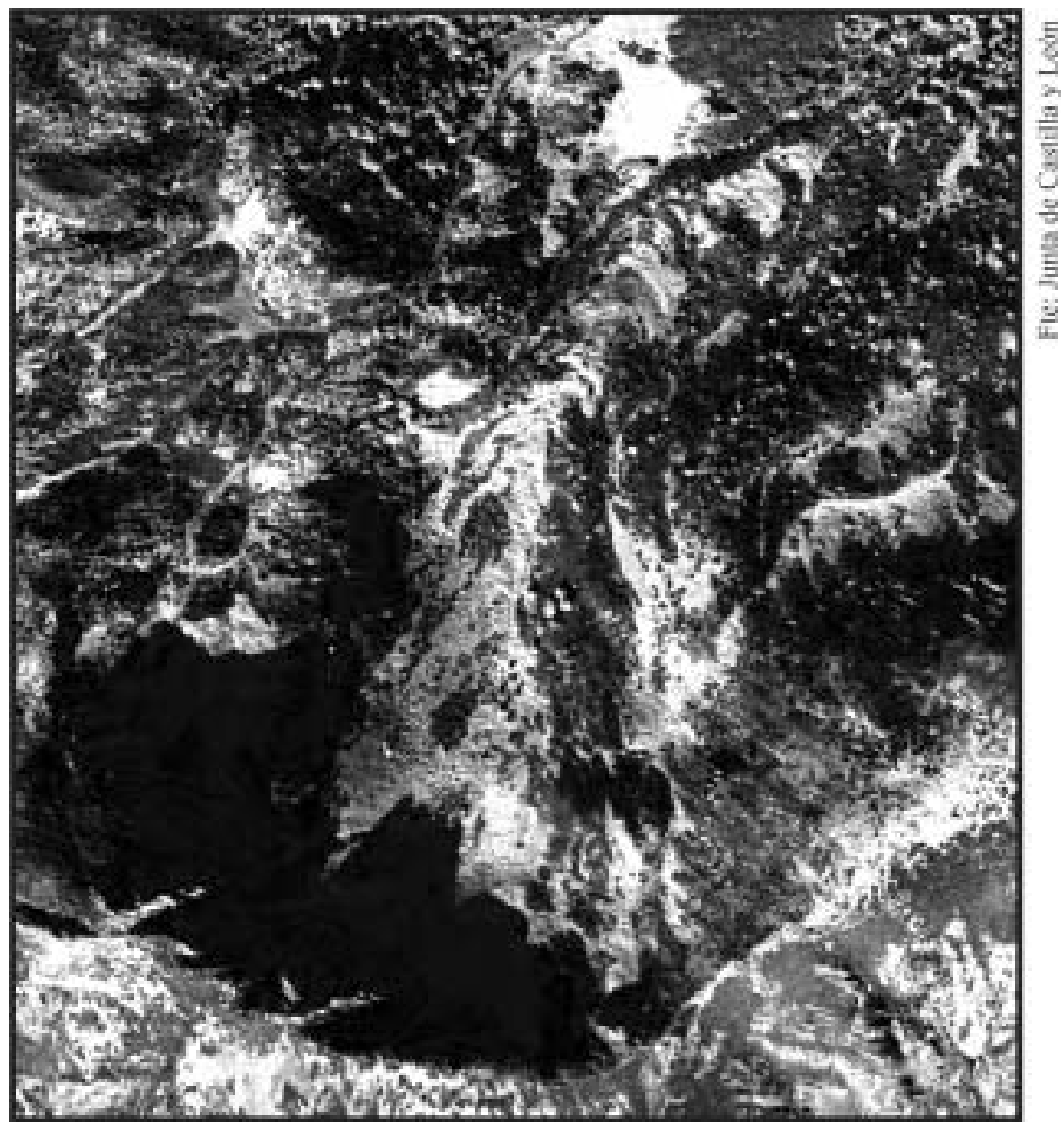

Foto 2. Glaciares rocosos situados en el circo de Peña Cefera. 
La Figura 3 muestra la distribución de los glaciares rocosos en función de la altitud y la orientación. La distribución altitudinal se ha hecho atendiendo a la altura de la raíz (altitud máxima) y del frente (altitud mínima), ordenados a partir de la altitud mínima de las raíces. Así, según la altitud de la raíz, que se refiere a la altura del punto medio donde comienza a desarrollarse el glaciar rocoso, se observa que casi el 70\% (Tabla 2) de ellos arrancan entre los 1800-2000 m (el 100\% de los glaciares rocosos complejos). Existe una diferencia significativa entre los glaciares rocosos de lengua y los lobulados: casi la mitad de las raíces de los primeros se inician en el intervalo de 1800-1900, mientras que en los lobulados esa frecuencia se da a mayor altitud (1900-2000). Por debajo de $1700 \mathrm{~m}$ arrancan tan sólo un 14\% de los glaciares rocosos, existiendo un intervalo altitudinal de transición (1700-1800 m) donde se localiza el 16\% de las raíces de los glaciares rocosos de lengua y lobulados. No se observa el inicio de ningún glaciar rocoso por debajo de los $1400 \mathrm{~m}$, constituyendo esta altitud un umbral límite para la formación de glaciares rocosos en la Sierra de Gistredo.

Tabla 2. Distribución (\%) de los glaciares rocosos en función de categorías altitudinales correspondientes a la raíz y frente.

\begin{tabular}{|c|cccc|}
\cline { 2 - 5 } \multicolumn{1}{c|}{$\begin{array}{c}\text { A. RAÍZ } \\
\text { mtrs }\end{array}$} & $\begin{array}{c}\text { Todos } \\
\text { los G.R. }\end{array}$ & $\begin{array}{c}\text { G.R. } \\
\text { de lengua }\end{array}$ & $\begin{array}{c}\text { G.R } \\
\text { lobulados }\end{array}$ & $\begin{array}{c}\text { G.R. } \\
\text { complejos }\end{array}$ \\
\hline $1400-1500$ & 2.3 & 3.4 & & \\
$1500-1600$ & 7 & 3.4 & 18.2 & \\
$1600-1700$ & 4.7 & 6.9 & & \\
$1700-1800$ & 16.3 & 20.7 & 9.1 & \\
$1800-1900$ & 44.7 & 48.3 & 27.3 & 66.7 \\
$1900-2000$ & 25 & 17.2 & 45.5 & 33.3 \\
\hline
\end{tabular}

\begin{tabular}{|c|cccc|}
\cline { 2 - 5 } \multicolumn{1}{c|}{$\begin{array}{c}\text { A. FRENTE } \\
\text { mtrs }\end{array}$} & $\begin{array}{c}\text { Todos } \\
\text { los G.R. }\end{array}$ & $\begin{array}{c}\text { G.R. } \\
\text { de lengua }\end{array}$ & $\begin{array}{c}\text { G.R } \\
\text { lobulados }\end{array}$ & $\begin{array}{c}\text { G.R. } \\
\text { complejos }\end{array}$ \\
\hline $1300-1400$ & 2.3 & 3.4 & & \\
$1400-1500$ & 4,7 & 6.9 & & \\
$1500-1600$ & 7 & 3.4 & 18.2 & 33.3 \\
$1600-1700$ & 16.3 & 20.7 & & 66.7 \\
$1700-1800$ & 34.9 & 37.9 & 18.2 & \\
$1800-1900$ & 18.6 & 17.2 & 27.3 & \\
$1900-2000$ & 16.3 & 10.3 & 36.4 & \\
\hline
\end{tabular}

La Tabla 2 refleja asimismo que las altitudes que alcanzan los frentes (altitud mínima) oscilan entre 1350-2000 m y el intervalo altitudinal más repetido corresponde a los 1700-1800 m (el 35\% de los glaciares rocosos tienen sus frentes en ese intervalo, así como el $37.9 \%$ de los de lengua). Para los glaciares rocosos lobulados, el intervalo más repetido corresponde una altitud superior (1900-2000 m), mientras que los frentes de los 
glaciares complejos se asientan sobre altitudes más moderadas (1500-1700 m). Un aspecto significativo es que la distribución de las altitudes de los frentes se hace a modo de dientes de sierra (Figura 3), relacionada directamente con las distintas formas de los glaciares rocosos, correspondiendo los picos más marcados y los mayores desniveles entre raíz y frente a glaciares rocosos de lengua y complejos.
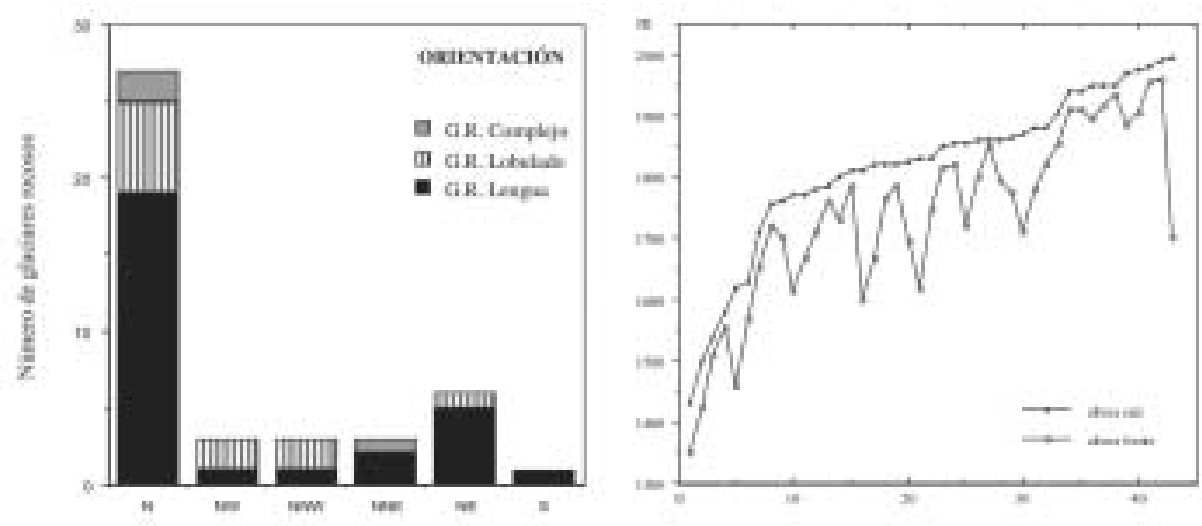

Figura 3. Distribución de los glaciares rocosos en función de la orientación y la altitud.

Las exposiciones de los glaciares rocosos son septentrionales, aunque hay una clase que predomina ampliamente sobre todas las demás, la estrictamente al $\mathrm{N}$, ya que casi los dos tercios de los glaciares rocosos (el $62.8 \%$ ) se orientan en esa dirección; este aspecto coincide con lo observado por varios autores para otros glaciares rocosos localizados en distintas montañas (White, 1979; Humlum, 1982). En menor medida destaca la orientación NE (14\%), mientras que en el resto de exposiciones (NNE, NW y NNW) los glaciares rocosos se reparten equitativamente (el $7 \%$ en cada case). Como muestra testimonial solo encontramos un glaciar rocoso de lengua con orientación $\mathrm{S}$, localizado a una elevada altitud (raíz a 1950 m.) y resguardado por las escarpadas paredes del circo de Valdeiglesia, cuya culminación supera ampliamente los $2000 \mathrm{~m}$ (2136). Si atendemos a la forma de glaciares rocosos observamos que los glaciares de lengua aparecen en todas las clases de exposición, aunque con preferencia (el 65.5\%) por la orientación N. Los glaciares rocosos lobulados muestran una distribución similar si bien no están presentes en exposiciones al NNE y sí son más abundantes que los de lengua en orientaciones abiertas al Oeste (NW y NNW). Los glaciares rocosos complejos, 2 se orientan al N y el tercero al NNE.

Respecto a las litologías, no se han establecido categorías dado que prácticamente todos los glaciares rocosos relictos están formados por cuarcitas del Paleozoico inferior, de la Formación Cándana y Serie de Los Cabos, cuyas litologías ocupan una amplia banda de dirección NO-SE, que forma el eje principal de las alineaciones montañosas de estas sierras. La Serie de Los Cabos abarca cronológicamente desde del Cámbrico medio 
hasta el Ordovícico inferior y está constituida por una alternancia de cuarcitas, de areniscas y de pizarras, con predominio de las primeras. El mejor ejemplo de ese control litológico en la génesis de los glaciares rocosos lo encontramos en el cordal que delimita el valle de Salentinos por el Sur. Este cordal presenta circos glaciares bien desarrollados en las cabeceras de todos los valles afluentes del río Salentinos por su margen izquierda; estos valles son de carácter obsecuente (Redondo et al., 2002a), con una orientación constante al NNE. Las cabeceras de estos valles coinciden con los afloramientos de las Capas de Transición ordovícicas, que se diferencian de los de la Serie de Los Cabos no sólo por su menor potencia, sino porque hay un predominio de facies pizarrosas, siendo los afloramientos cuarcíticos de menor extensión y espesor; en todo este sector hay media docena de circos en cuyo seno no encontramos verdaderos glaciares rocosos, sí acaso algunos pequeños lóbulos embrionarios. Cuando el cordal gana en altitud, manteniendo la misma dirección, pero arma sobre las series cuarcíticas del techo de la Serie de Los Cabos, aparecen glaciares rocosos relictos de morfología lobulada o de lengua, muy colonizados por la vegetación, "acogidos" por los circos glaciares.

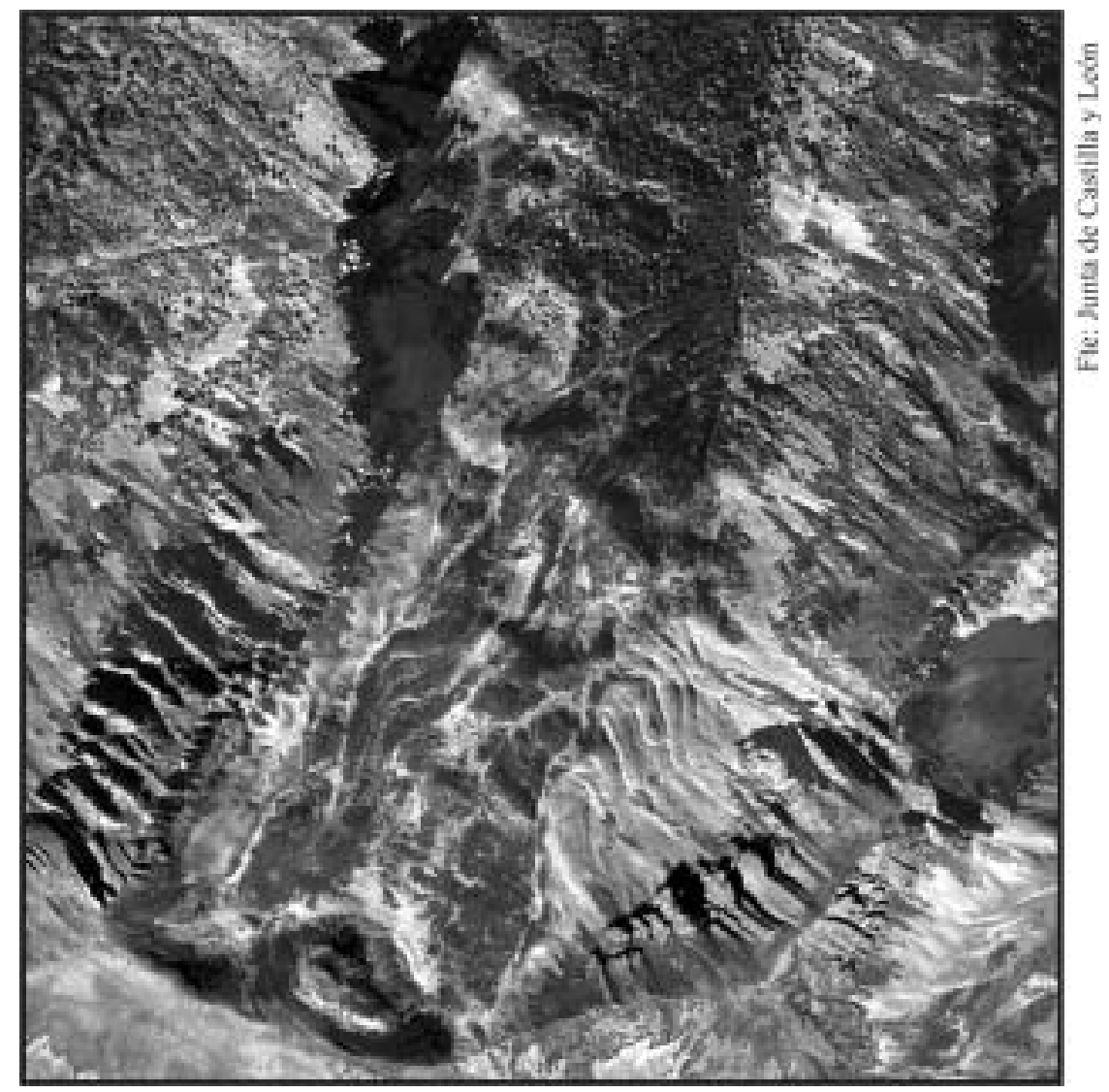

Foto 3. Glaciares rocosos situados en el circo de Braña La Pena. 
Más al Sur, en los cordales meridionales de la Sierra de Gistredo, hay un predominio de litologías pizarrosas, primero con la $\mathrm{fm}$ Pizarras de Luarca que se constituyen como una potente sucesión de pizarras negras de grano fino, muy compactas y homogéneas, y más al Sur aún, con la fm Agüeira, constituida por una alternancia de areniscas, pizarras y con niveles cuarcíticos intercalados. El cordal principal de este sector, hacia el Este, presenta algunos circos y nichos bien desarrollados a partir de las litologías pizarrosas, pero no se ha detectado la presencia de restos de glaciares rocosos, ni siquiera en estado embrionario. Por otro lado, la presencia hacia el techo de la fm Agüeira, de bancos de cuarcitas blancas, no parece haber tenido importancia en la génesis de los glaciares rocosos relacionado, al parecer, con la posición más meridional de los afloramientos y su más baja altitud.

Hacia el NNE del afloramiento de la Serie de los Cabos se suceden la $f m$ Calizas de Vegadeo, sin trascendencia geomorfológica en esta área y la fm Cándana-Herrería, algo más extensa y compuesta por una sucesión de calizas, microconglomerados, pizarras y cuarcitas; estas últimas suelen aflorar con bastante regularidad y con potencias decimétricas, pero muy entreveradas dentro de la formación con otras litologías más pizarrosas y areniscosas, por lo cual no constituyen buenos resaltes para generar glaciares rocosos, y ello a pesar de que uno de los relieves culminantes de estas sierras, el Tambarón (2102 $\mathrm{m}$.), arma sobre estos materiales.

Finalmente, más hacia el NNE, los cordales septentrionales de las Sierras se estructuran a partir de los materiales precámbricos de la Serie Villalba en la que hay, otra vez, un predominio casi absoluto de litologías pizarrosas de elevada friabilidad, de tal modo que el cordal principal del Nevadín (2082 m.), a pesar de presentar unos circos muy bien desarrollados, sobre todo en los valles con orientación N, los glaciares rocosos en alguna de sus morfologías o grados de desarrollo son inexistentes o no se han conservado. La litología se constituye, de este modo, como un factor estructural básico tal y como apreciamos en los estudios preliminares (Redondo et al., 1998)

\subsection{Caracterización y relaciones morfométricas de los diferentes tipos de glaciares rocosos}

La Tabla 3 recoge la gran variabilidad que muestran los rasgos morfométricos de los glaciares rocosos de lengua y lobulados, y de sus áreas fuente. Los datos de glaciares rocosos complejos, dado que sólo son tres, los hemos incluido aparte, en la Tabla 4.

Los glaciares rocosos de lengua son estrechos (162 m, intervalo dominante 100-200 m) y largos (309,2 m de media), con una marcada agrupación en la clase de 200-300 m.; éstos valores se corresponden con los de otros glaciares rocosos estudiados en otras áreas de montaña del mundo (Calkin et al., 1987) aunque no con los señalados por White (1979) y Gorbunov (1983), > 600 m. Mantienen una área media importante, de varias decenas de Ha, si bien muestran un amplio rango de valores (entre 4.595 y $130.463 \mathrm{~m}^{2}$ ). El desnivel entre raíz y frente no es muy acusado, siendo el valor medio <100 m, a la vez que se concentran de manera muy acusada en las clases menores, entre 25-75 m. La 
pendiente media en superficie es de $16,5^{\circ}$, aunque todos presentan sectores internos de mayor pendiente, generalmente los más próximos a la raíz, y otros de pendiente más suave, en las proximidades del frente.

Tabla 3. Rasgos morfométricos de los glaciares rocosos de lengua y lobulados.

\begin{tabular}{|l|c|c|c|c|c|}
\multicolumn{1}{c|}{} & Media & C.V. & \begin{tabular}{c} 
Valor \\
mínimo \\
\multicolumn{1}{c|}{}
\end{tabular} & $\begin{array}{c}\text { Galor } \\
\text { máximo }\end{array}$ & $\begin{array}{c}\text { Moda } \\
\text { (intervalo) }\end{array}$ \\
\hline L. (m) & 309 & 63,4 & 90,3 & 773 & $200-300$ \\
\hline A (m) & 162 & 45,6 & 61,1 & 314,1 & $100-200$ \\
\hline L/A & 1,9 & 43,7 & 1 & 3,8 & $1-2$ \\
\hline AGR. (m²) & 34264 & 91,2 & 4595 & 130463 & $0-25000$ \\
\hline Ar (m) & 1807 & 7,2 & 1430 & 1990 & $1800-1900$ \\
\hline Af. (m) & 1719 & 8,4 & 1350 & 1960 & $1700-1800$ \\
\hline Drf. (m) & 87,6 & 57,8 & 25 & 210 & $25-75$ \\
\hline PG.R. $\left.{ }^{(}\right)$ & 16,5 & 25 & 8 & 27 & $15-20$ \\
\hline Aaf (m) & 1950 & 7,2 & 1650 & 2.236 & $1900-2100$ \\
\hline P.af $\left({ }^{\circ}\right)$ & 33,7 & 20,5 & 20 & 53 & $30-40$ \\
\hline Dafr G.R. & 140,5 & 50,3 & 45 & 317 & $100-200$ \\
\hline
\end{tabular}

\begin{tabular}{|c|c|c|c|c|}
\hline \multicolumn{1}{|c}{ Glaciares rocosos lobulados } \\
\hline Media & C.V. & $\begin{array}{c}\text { Valor } \\
\text { mínimo } \\
\text { o }\end{array}$ & $\begin{array}{c}\text { Valor } \\
\text { máximo }\end{array}$ & $\begin{array}{c}\text { Moda } \\
\text { (intervalo) }\end{array}$ \\
\hline 56 & 43,5 & 21,3 & 90 & $30-40$ \\
\hline 178 & 40,2 & 70,6 & 323 & $100-200$ \\
\hline 0,3 & 34,1 & 0,1 & 0,5 & $0-1$ \\
\hline 7604 & 52,5 & 1529 & 12785 & $0-15000$ \\
\hline 1830 & 8,2 & 1540 & 1980 & $1900-2000$ \\
\hline 1799 & 8,4 & 1510 & 1955 & $1900-2000$ \\
\hline 30,9 & 46,2 & 10 & 60 & $30-40$ \\
\hline 29,5 & 25,6 & 16 & 38 & $30-40$ \\
\hline 1925 & 6 & 1650 & 2046 & $2000-2100$ \\
\hline 29,5 & 25,6 & 16 & 38 & $30-40$ \\
\hline 95,2 & 53,8 & 59 & 239 & $0-100$ \\
\hline
\end{tabular}

Los glaciares rocosos lobulados, representantes más típicos de los denominados talus rockglacier para muchos autores, se caracterizan, por el contrario, por ser más anchos (valor medio $178 \mathrm{~m}$ ) que largos (55,9 m.). La relación L/A, que es un indicador de su forma en planta, refleja efectivamente las diferencias en este sentido entre los dos tipos de glaciares rocosos: valor de L/A $<1(0,3)$ para los lobulados frente a valores $>1$ $(1,9)$ para los de lengua. Su superficie media $\left(7604 \mathrm{~m}^{2}\right)$ y su desnivel entre raíz y frente $(30,9)$ presentan valores más modestos que en el caso de los glaciares rocosos de lengua, pero no así su pendiente que es mucho más acusada $(29,5)$, con un rango de valores, además, muy por encima de los estimados por otros autores para este tipo de glaciares rocosos, localizados en ambientes más favorables.

Otro de los resultados de este análisis es que ambos tipos de glaciares rocosos no muestran diferencias respecto a la altitud media de sus raíces, en torno a $1.800 \mathrm{~m}$., pero sí respecto a clases dominantes, de tal forma que los lobulados arrancan en un porcentaje elevado por encima de los $1.900 \mathrm{~m}$ frente a los de lengua, que lo hacen a una altitud inferior (1.800-1.900 m.). Las diferencias se acentúan más cuando se trata de la altura de sus frentes. Las altitudes medias de las áreas fuente no difieren en sus valores medios, que rondan los 1925-50 m., pero sí hay diferencias en su pendiente media y, sobre todo, en los valores de los desniveles altitudinales entre la raíz del glaciar y la altitud máxima del área fuente, siempre más fuertes en las áreas que alimentan a los glaciares rocosos de lengua. 
La aplicación de un índice estadístico inferencial (Test de la t) a los valores medios, recogidos en la Tabla 3, de todas las variables morfométricas de ambos tipos de glaciares rocosos ha permitido, efectivamente, comprobar y corroborar que existen diferencias altamente significativas (> al 99\%) entre cinco de sus parámetros básicos: longitud, relación $\mathrm{L} / \mathrm{H}$, pendiente, desnivel y tamaño de los glaciares rocosos. La significación estadística se reduce $90 \%$ cuando se trata de la altitud del frente, más elevada en el caso de los glaciares rocosos lobulados, y no existen diferencias significativas entre la anchura y la altitud de la raíz, cuyos valores son muy similares en ambos casos.

En la Tabla 4 aparecen los rasgos morfométricos de cada uno de los tres glaciares rocosos complejos identificados en la Sierra de Gistredo. Los dos primeros se localizan en el cordal de Valdeiglesias. El $1^{\circ}$ se ubica en la vertiente orientada al Este y el aporte de clastos desde el cordal N-S de Pico Lago, a partir de numerosos pasillos estructurales, ha dado lugar a múltiples lóbulos que por coalescencia generaron crestas y surcos longitudinales que corren subparalelos al pie del talud de derrubios. Destaca su densa colonización vegetal, excepto en la zona interior del frente, donde aún son visibles ocho surcos y crestas transversales. Es el más largo de los 43 seleccionados, el de mayores dimensiones y el que arranca a mayor altitud. El $2^{\circ}$ se sitúa en el mismo cordal que el anterior pero en la vertiente orientada al Oeste y presenta cinco/seis lóbulos que se han unido y deformado en el sentido de la pendiente, apoyándose su frente sobre una pequeña cubeta de sobreexcavación glaciar. A pesar de estar menos colonizado por la vegetación su morfología es menos clara. Ambos muestran una relación L/A muy superior a 1 indicando que se trata de glaciares rocosos mucho más largos que anchos. Sus pendientes son moderadas. El $3^{\circ}$ se localiza en el Cordal del Catoute, caracterizado por un aspecto más macizo y de mayor anchura en sus cumbres que el resto de los cordales. Está compuesto por una agregación de multilóbulos, pegados al pie del canchal y bordeándolo, lo que explica que su anchura sea mucho mayor que su longitud (L/A: 0,45). Tiene unas dimensiones importantes (37 Ha) y un desnivel y pendiente menos marcadas en comparación con los dos anteriores.

Tabla 4. Rasgos morfométricos de los glaciares rocosos complejos.

\begin{tabular}{|l|c|c|c|}
\hline G.R complejo & G.R. $\mathbf{l}$ & $\boldsymbol{G . R} . \mathbf{2}$ & G.R.3 \\
\hline Longitud (m) & $1.204,6$ & 574,4 & 185,06 \\
\hline Anchura (m) & 233,3 & 250,68 & 413,34 \\
\hline Relación Longitud/Anchura & 5.17 & 2,99 & 0,45 \\
\hline Superficie (m $\left.{ }^{2}\right)$ & 176.130 & 114.297 & 37.285 \\
\hline Altitud de la raíz (m) & 1.995 & 1.820 & 1.820 \\
\hline Altitud del frente (m) & 1.700 & 1.670 & 1.785 \\
\hline Desnivel raíz/frente (m) & 295 & 150 & 35 \\
\hline Pendiente glaciar rocoso $\left(^{\circ}\right)$ & 14 & 15 & 11 \\
\hline
\end{tabular}


De los análisis anteriores se resuelve que los diferentes tipos de glaciares rocosos muestran una gran diversidad de tamaños, desniveles y pendientes. Se asientan sobre diversas topografías (en el fondo de los circos sobre pequeñas cubetas de sobreexcavación, al pie de taludes de derrubios, sobre umbrales glaciares) pero siempre por encima de los $1400 \mathrm{~m}$. de altitud. Además, todos ellos sienten preferencia por la orientación umbría y se desarrollan a partir de una misma litología.

Con el fin de analizar las interrelaciones o el nivel de dependencia entre los distintos rasgos morfométricos de los glaciares rocosos hemos llevado a cabo una serie de análisis estadísticos sencillos. La Tabla 5 muestra los resultados de las correlaciones simples, establecidas para observar la medida del grado de asociación entre los rasgos morfométricos de los glaciares rocosos de lengua y de los lobulados (se han desestimado los glaciares rocosos complejos dado que su escasa representación no permite llevar a cabo análisis de este tipo significativos) y de sus áreas fuente. En este sentido, se han incluido la altitud, pendiente y desnivel del área fuente como variables que a priori pueden influir en determinados parámetros geométricos. Los análisis muestran, en ambos tipos de glaciares rocosos, que existen correlaciones altamente significativas (> al 99\% y $95 \%$ ) y repetitivas entre determinadas variables. Así, el tamaño de los glaciares rocosos de lengua se relaciona directamente con su longitud y anchura y con el desnivel que existe entre raíz y frente; las variables seleccionadas sobre el área fuente no resultan; la relación es obvia entre la altitud máxima y mínima del glaciar rocoso y la del área fuente. Por otro lado, mientras el desnivel está controlado por la longitud, anchura, L/A y tamaño del glaciar, su pendiente no parece depender de ninguna de las variables consideradas, entrando en juego otros rasgos como la topografía subyacente y la propia morfología superficial del glaciar rocoso.

Tabla 5. Matriz de correlaciones entre los parámetros morfométricos y altitudinales de los glaciares rocosos y de sus áreas fuente.

\begin{tabular}{|c|c|c|c|c|c|c|c|c|c|c|c|}
\hline & \multicolumn{11}{|c|}{ Glaciares rocosos lobulados } \\
\hline & $\begin{array}{l}\text { Longitud } \\
\text { G.R. }\end{array}$ & $\begin{array}{c}\text { Anchura } \\
\text { G.R. }\end{array}$ & $\mathrm{L} / \mathrm{A}$ & $\begin{array}{c}\text { Superficie } \\
\text { G.R }\end{array}$ & $\begin{array}{c}\text { Altura } \\
\text { raíz }\end{array}$ & $\begin{array}{l}\text { Altura } \\
\text { frente }\end{array}$ & $\begin{array}{c}\text { Desnivel } \\
\text { G.R. }\end{array}$ & $\begin{array}{l}\text { Pendiente } \\
\text { A. fuente }\end{array}$ & $\begin{array}{c}\text { Pendiente } \\
\text { G.R. }\end{array}$ & $\begin{array}{c}\text { Altitud } \\
\text { A.fuente }\end{array}$ & $\begin{array}{l}\text { Desnivel } \\
\text { Af/raíz }\end{array}$ \\
\hline $\mathrm{L}(\mathrm{m})$ & - & .3 & $.7^{* *}$ & $.9 *$ & .2 & .1 & $.7 * *$ & .1 & -.3 & .2 & -.1 \\
\hline $\mathrm{A}(\mathrm{m})$ & $.7 *$ & . & -.4 & $.7^{* *}$ & .3 & .3 & .1 & .1 & $-.6 * *$ & .3 & -.1 \\
\hline $\mathrm{L} / \mathrm{A}$ & $.7^{*}$ & -.037 & - & .3 & -.1 & -.2 & .5 & -.1 & -.17 & -.1 & .2 \\
\hline AGR & $.9^{*}$ & $.8^{*}$ & .4 & . & .3 & .2 & $.6^{* *}$ & .2 & -.4 & .3 & -.2 \\
\hline $\operatorname{Ar}(\mathrm{m})$ & .02 & -.1 & .004 & .007 & - & $1^{*}$ & -.1 & -.5 & -.3 & $1^{*}$ & $-.7 * *$ \\
\hline Af (m) & -.3 & -.3 & -.3 & -.3 & $.9 *$ & . & -.2 & -.5 & -.3 & $1^{*}$ & $-.7 * *$ \\
\hline $\operatorname{Dgr}(\mathrm{m})$ & $.9 *$ & $.6^{* *}$ & $.6^{* *}$ & $.9 *$ & -.1 & -.4 & - & .2 & .3 & -.1 & -.1 \\
\hline $\operatorname{Paf}\left({ }^{\circ}\right)$ & .1 & -.02 & .1 & .1 & .3 & .3 & .1 & - & .2 & -.5 & .4 \\
\hline $\operatorname{PGR}\left({ }^{\circ}\right)$ & -.3 & -.3 & -.2 & -.3 & -.1 & -.1 & -.018 & .022 & - & -.4 & -.2 \\
\hline $\operatorname{Aaf}(\mathrm{m})$ & .1 & .003 & .009 & .1 & $.9^{*}$ & $.8^{*}$ & .049 & $.5^{* *}$ & .042 & - & -.5 \\
\hline Dafr (m) & .2 & .2 & .2 & .3 & -.1 & -.2 & .3 & $.4 * *$ & .2 & $.4^{* *}$ & - \\
\hline
\end{tabular}

Glaciares rocosos de lengua

* nivel de confianza superior al $99 \%$

** nivel de confianza superior al $95 \%$ 
La matriz de correlación referida a los glaciares rocosos lobulados (Tabla 5) refleja alguna diferencia significativa respecto a los de lengua, cuando se trata de la pendiente del glaciar rocoso y de su altitud (altura de la raíz y frente), de manera que tienden a ubicarse a mayor altitud cuanto mayor es la altura de la divisoria al pie de la cual se asientan, mientras que la pendiente del glaciar rocoso sólo guarda cierta relación con la anchura pero, considerada como único factor, no contribuye de forma clara a explicar la pendiente.

Finalmente, a modo de resumen, la Tabla 6 recoge los datos de las variables que caracterizan a cada uno de los tres grupos de glaciares rocosos y sus áreas fuente y se han comparado mediante análisis de la Varianza (ANOVA). Al realizar los contrastes por pares se obtiene una relación significativa al 95\% (test F de Scheffe; p > 0.05) en la mayoría de los casos. Las letras minúsculas diferentes indican diferencias significativas entre las medias de cada variable. Del análisis de la Tabla 6 se recogen los siguientes resultados:

a) Los tres grupos presentan características similares en cuanto a altitudes, tanto en lo que se refiere a la altitud del área fuente (altitud máxima de la divisoria) como en cuanto a la localización o instalación de los glaciares rocosos (alturas del frente y de la raíz); este último aspecto es importante porque ayuda a establecer de forma ajustada la línea altitudinal de iniciación de los glaciares rocosos (RILA, Humlum, 1988).

b) Las variaciones más altamente significativas entre los tres grupos de glaciares rocosos se refieren a algunos de los parámetros que mejor perfilan y discriminan la geometría y forma de los glaciares rocosos como son la longitud, área, pendiente y relación L/A (parámetro que sirve como base para establecer su clasificación en lobulados, de lengua y complejos).

c) Las variables referidas a las características del área fuente aportan también resultados interesantes de manera que los glaciares rocosos de lengua se desarrollan a partir de paredes más escarpadas que los lobulados y, más aún, que los complejos, a la vez que estos últimos, su localización mantiene un mayor desnivel con respecto a la divisoria localizada inmediatamente por encima de su raíz. Por otro lado, la pendiente de los glaciares rocosos lobulados (caracterizados por una menor longitud) guarda un mayor grado de continuidad con respecto a la de su área fuente $\left(29,5^{\circ}\right.$ y $26,1^{\circ}$ respectivamente $)$ que en el caso de los de lengua y complejos. 
Tabla 6. Valores medios y significación estadística (p) de los análisis de la varianza de las variables morfométricas para los tres grupos de glaciares rocosos.

\begin{tabular}{|c|c|c|c|c|}
\hline & $\begin{array}{c}\text { G.R. lengua } \\
\text { ( a ) }\end{array}$ & $\begin{array}{c}\text { G.R. lobulado } \\
\text { ( b ) }\end{array}$ & $\begin{array}{c}\text { G.R. Complejo } \\
\text { ( c ) }\end{array}$ & $\mathbf{p}$ \\
\hline $\begin{array}{l}\text { Longitud (m) } \\
0.0001\end{array}$ & & $309 *$ & $56 *$ & $654,8^{*}$ \\
\hline Anchura (m) & $162 \mathrm{c}$ & 178 & $299 \mathbf{a}$ & 0.0163 \\
\hline $\mathrm{L} / \mathrm{A}$ & $1,9 *$ & $0,3 *$ & $2,6^{*}$ & 0.0001 \\
\hline Superficie $\left(\mathrm{m}^{2}\right)$ & $34264 *$ & $7604 *$ & $176130 *$ & 0.0001 \\
\hline Altitud raíz (m) & 1807 & 1830 & 1878 & 0.6457 \\
\hline Altitud frente (m) & 1719 & 1799 & 1718 & 0.2908 \\
\hline D. raíz/frente (m) & $87,6 \mathbf{b}$ & 30,9 a c & $160 \mathrm{~b}$ & 0.0007 \\
\hline Pendiente G.R. $\left({ }^{\circ}\right)$ & $16,5 \mathbf{b}$ & 29,5 a c & $19,3 \mathbf{b}$ & 0.0001 \\
\hline Alt. divisoria (m) & 1950 & 1925 & 2063 & 0.2810 \\
\hline P. área fuente $\left({ }^{\circ}\right)$ & $33,7 \mathbf{b}$ & 26,1 a c & $23,7 \mathbf{b}$ & 0.0041 \\
\hline Des. af./raíz G.R. & 140,5 & $95,2 \mathbf{c}$ & $185,3 \mathbf{b}$ & 0.0717 \\
\hline
\end{tabular}

* indica diferencias altamente significativas entre los tres grupos.

\section{Discusión de resultados}

En la Sierra de Gistredo se han analizado 43 glaciares rocosos relictos que se asientan sobre formas erosivas de origen glaciar, lo que permite considerarlos como resultado de unas condiciones morfogenéticas claras de tipo periglaciar, que constituyen la transición entre el final del periodo glaciar (etapa de los glaciares de circo) y las condiciones actuales. Su forma en planta ha permitido clasificarlos como lobulados, de lengua y complejos. Este estudio demuestra que algunas variables geoambientales (litología, exposición y altitud) influyen de forma decisiva en la localización y forma de los glaciares rocosos, mientras que determinados parámetros morfométricos de su área fuente contribuyen poco a definir algunos de sus rasgos más distintivos:

a) Litología. La práctica totalidad de los glaciares rocosos se han formado sobre y a expensas de las series cuarcíticas del Paleozoico inferior, de tal forma que hay una correspondencia absoluta entre los afloramientos de cuarcitas y la génesis de estas formas periglaciares, hecho ya apuntado para las Sierras de Degaña (Alonso, 1989) y Laciana (Alonso y Corte, 1992). De hecho, las principales concentraciones de glaciares rocosos, aparecen ligados a la presencia de afloramientos de la Serie de Los Cabos, cuyas litologías ocupan una amplia banda de dirección NO-SE que forma el eje principal de las alineaciones montañosas de estas sierras; así los glaciares rocosos aparecen, en primer lugar, en torno al pico Valdeiglesia $(2136 \mathrm{~m})$ y en la prolongación de su cordal hacia el E y, en $2^{\circ}$ lugar, en torno a los cordales del pico Arcos del Agua (2063 m) y en el cordal principal del Catoute (2112 m), todos con orientación Norte. 
En las fábricas realizadas en glaciares rocosos (Redondo et al., 2002b), la cuarcita representa más del 90\% de las litologías de las muestras y las areniscas tienen una representación testimonial. Los clastos de pizarra no suelen aparecer, a pesar de estar presentes en las estructuras de sus áreas fuente. Dos factores han influido en ese hecho. El $1^{\circ}$ es estructural: las pizarras se localizan intercaladas en finas capas, entre bancos más potentes de cuarcita y arenisca. En $2^{\circ}$ lugar, se trata de pizarras de alta friabilidad, con lo que su alteración parece asegurada; por eso, el tiempo transcurrido desde la formación de los glaciares rocosos ha podido permitir la desaparición de los fragmentos de pizarra que pudieron contener, al ser aquéllos menos numerosos, de menor tamaño y muy alterados. Además de la litología, la forma de presentarse la roca, que depende de su condición litoestructural, parece que influye en la génesis de los glaciares rocosos ya que, como demostraron Wahrhaftig \& Cox (1959), las rocas que se fragmentan a partir de la pizarrosidad y esquistosidad son desfavorables para la formación de glaciares rocosos, mientras que las más competentes y compactas sí son favorables.

Redondo et al., (1998) habían puesto en evidencia la conservación y el notable desarrollo de glaciares rocosos, sólo cuando en las paredes de circo en cuyo fondo se asientan afloran cuarcitas cámbricas de la Serie Los Cabos. Si esta litología no está presente en los cordales de las divisorias, los glaciares rocosos o no están presentes, o sólo muestran un desarrollo embrionario, de tal forma que hoy en día, al tratarse de formas relictas, apenas son perceptibles. Pero además, la constatación de que no en todos los fondos de circo de la Sierra de Gistredo se han desarrollado estas formas, habiendo en algunos casos importantes afloramientos de cuarcitas que sí han generado glaciares rocosos en otros circos que debieron estar en condiciones paleoclimáticas similares, permite sospechar la existencia de un factor estructural añadido. Dicho factor está muy relacionado con la densa y regular fracturación de sus macizos de alimentación y con la particular disposición de las discontinuidades respecto al relieve (Evin, 1985, 1988). Los glaciares rocosos más desarrollados y mejor definidos (de lengua y mixtos) se sitúan al pie de paredes extensas, con estratos de buzamiento subvertical y a favor de la pendiente, dispuestos paralelos o subparalelos a los planos de las paredes de fondo de los circos. En estos casos, la estratificación y su familia de diaclasas paralelas son los principales responsables del aporte de derrubios al glaciar rocoso, aporte realizado por caídas o deslizamientos frontales; mientras que las diaclasas transversales, juegan un papel secundario, aunque importante, favoreciendo el desalojo de material por los extremos de la pared (aporte por caídas o deslizamientos "laterales"). Los glaciares rocosos lobulados se localizan en los flancos de los circos, como sucede en Arcos del Agua, bajo macizos o alineaciones de dimensiones mucho más reducidas y en los que la dirección de los estratos es perpendicular u oblicua al plano de la ladera. Aquí, los aportes más importantes han sido laterales y han corrido a cargo de las familias de diaclasas paralelas al plano de la ladera. Estos aspectos manifiestan un rígido control litoestructural en la génesis y desarrollo de los glaciares rocosos.

b) Exposición. Los glaciares rocosos muestran una preferencia por orientaciones septentrionales, tanto más al $\mathrm{N}$ cuanto más desarrollada está la forma. Los glaciares rocosos, sobre todo los de lengua y complejos, se localizan de forma preferente en el 
fondo de los circos glaciares orientados al N; los lobulados, además de en la orientación norteña, suelen orientarse hacia el NW y NNW, ocupando los flancos de los circos glaciares. Esta relación entre exposiciones umbrías y la presencia de glaciares rocosos ha sido analizada por varios autores en distintos ambientes montañosos (Calkin et al., 1987; Sloan \& Dyke, 1998; Humlum, 2000) y en nuestro país. Así, Chueca (1989) señala que en el Pirineo oscense, el $69 \%$ de los glaciares rocosos se orientan hacia el N o el NE y se indica que se orientan más hacia el $\mathrm{N}$ que los circos glaciares en los que suelen insertarse. Serrano y Agudo (1998) comprobaron igualmente que los glaciares rocosos activos se orientan preferentemente en sentido NO-N-NE, datos que coinciden con los expuestos por Barsch (1996), quien señala que en casi todas las montañas medias del hemisferio Norte estas formas se desarrollan preferentemente con esas exposiciones. Hay que suponer que esa orientación, casi al N, que presentan estas formas relictas, manifiesta una menor tolerancia a la exposición solar directa, que impediría la persistencia del hielo intersticial, o de los núcleos de hielo, cuando eran funcionales. Es decir, no sólo eran necesarias altas y desarrolladas paredes de circo que generaran abundantes aportes de material al glaciar, sino que fueran también lo suficientemente verticales para proyectar sombra el mayor número de horas posible, a fin de asegurar la permanencia del hielo intersticial. Los glaciares rocosos al pie de grandes paredes verticales reciben como mínimo un $8 \%$ menos de radiación solar directa que las morrenas de los circos glaciares situadas en sus márgenes (Calkin et al., 1987).

Además, las condiciones del relieve inicial, es decir la forma y extensión de los afloramientos cuarcíticos que forman su área fuente, constituye un factor de primer orden que se relaciona con el factor orientación que, a su vez controló una evolución morfogenética dispar en las vertientes septentrionales y meridionales de los cordales montañosos. La asimetría que caracteriza los sectores altos de las laderas, es fruto de un proceso de excavación glaciar previo marcadamente asimétrico, por el cual, las vertientes septentrionales experimentaron una excavación por el hielo de los circos glaciares con extensas paredes verticales que serán el área fuente de los glaciares rocosos posteriores, mientras que la ocupación por el hielo de las cabeceras fluviales preglaciares orientadas al Sur fue menos intensa y duradera, de manera que apenas se insinuaron unos circos que dejaron poca superficie de afloramiento de rocas cuarcíticas en condiciones subaéreas. En la vertiente septentrional, por el contrario, es donde los glaciares rocosos se desarrollaron al amparo de unos afloramientos rocosos más extensos que surgen con la fusión del hielo de los glaciares, apareciendo casi siempre de forma clara la convergencia espacial de formas glaciares, a las que se superponen y fosilizan, y las de tipo periglaciar, bajo la forma de glaciares rocosos de lengua, lobulados o complejos en función del volumen del aporte de cada emplazamiento concreto.

c) Altitud. Este factor es claramente determinante también en la génesis de los glaciares rocosos puesto que es el que impone unas determinadas condiciones climáticas tanto locales como, sobre todo, zonales, a través de un determinado gradiente térmico (Evin \& Fabre, 1990). Por eso resulta de sumo interés conocer a partir de que nivel altitudinal, o entre que niveles, se desarrollan estas formas porque ello nos permite una aproximación a las características paleoclimáticas en el caso de los glaciares rocosos 
fósiles. Siguiendo la propuesta de Humlum $(1988,2000)$ basada en el establecimiento de una línea, coincidiendo de forma aproximada con la raíz, a partir de la cual aparecen los glaciares rocosos (RILA; rock glacier initiation line altitude), en la Sierra de Gistredo, la posición de la RILA ha sido calculada, para la mayoría de los casos, en torno a los 1800-1850 m, tal como revelan los datos referidos a la altura de sus raíces, aunque se observa una clara disimetría entre las vertientes más septentrionales (que soportan la mayoría de las formas) donde algunas formas lobuladas se inician sobre todo en la cota de 1900 m. Además, factores topoclimáticos y estructurales hacen que en el extremo occidental del cordal de Valdeiglesia-Lago, descienda la RILA por debajo de la cota de $1700 \mathrm{~m}$, lo mismo que en el extremo oriental del cordal Arcos del Agua-Los Infiernos, o en el extremo occidental del Catoute, donde desciende netamente por debajo de la cota de los $1700 \mathrm{~m}$; en el primer y último caso se trata de pequeños glaciares rocosos lobulados, mientras que en el segundo caso se trata de un glaciar rocoso de lengua localizado a más baja cota.

d) Los parámetros analizados en este trabajo, referidos a aspectos de la geometría o forma de los glaciares rocosos, nos han permitido discriminar y definir claramente los glaciares rocosos de lengua, lobulados y complejos (Wahrhaftig \& Cox, 1959; Humlum, 1982; André, 1992). Los primeros son más grandes, largos y estrechos y poseen una menor pendiente superficial que los lobulados, caracterizados por una pendiente media muy acusada y un menor desnivel superficial y tamaño. Los complejos destacan principalmente por su gran tamaño y longitud y una pendiente moderadas, aspectos que en este caso están muy vinculados a su grado de complejidad (Barsch, 1987). Hemos observado que predominan los glaciares rocosos de lengua, lo cual da una idea de la persistencia en el tiempo de unas condiciones ambientales de tipo periglaciar que hicieron posible la génesis de este tipo de formas. Los más largos tienen el frente apoyado en un umbral glaciar en el que las cuarcitas aparecen cortadas a bisel por la acción del hielo glaciar y otros (sector Arcos del Agua) se sobreimponen netamente a la última generación de morrenas, como ocurre en otros sectores de la Cordillera Cantábrica (Jiménez, 1996).

Las relaciones establecidas para el área y pendiente de los glaciares rocosos son evidentes y altamente significativas cuando se trata de aquellos parámetros que atañen específicamente a la morfología superficial (longitud, anchura, desnivel, L/A). Sin embargo, el escaso nivel de asociación de que muestran con las variables referidas al área fuente (altitud, desnivel y pendiente) indican que su grado de control sobre éstos dos parámetros es bastante limitado. Para algunos autores (Barsch, 1977; las relaciones entre la superficie de los glaciares rocosos y otros parámetros de su área fuente son problemáticas, especialmente para los de mayores dimensiones dado que su desarrollo abarca largos periodos de tiempo y las relaciones pueden quedar enmascaradas por la combinación de distintos procesos y donde algunos factores como los morfoestructurales (no reflejados en las variables morfométricas del área fuente) juegan un papel fundamental. Así, en el diferente desarrollo que alcanzan las lenguas de los glaciares rocosos de la Sierra de Gistredo, tanto en longitud como en la superficie que ocupan, han influido entre otros factores, la disponibilidad de material suministrado por el área fuente, que 
tiene que ver con la extensión del afloramiento lo cual depende, a su vez, de la intensidad de la excavación glaciar y de la disposición de las redes de discontinuidades de las rocas respecto a los planos de la ladera. En cuanto a la pendiente, también entran en juego otros factores, algunos difícilmente definibles como es la "rugosidad"·del relieve subyacente, sobre el que se asienta el glaciar rocoso, que da lugar a rupturas de pendiente locales, y la propia morfología de su superficie, a base de surcos y crestas, contribuyendo ambos hechos a controlar su pendiente final.

\section{Agradecimientos}

Este trabajo ha sido realizado con el apoyo del trabajo de investigación: Estudio de los glaciares rocosos del Macizo del Catoute (Montaña Cantábrica, León). Bases para su conocimiento y valoración como Paisaje Natural. Programa Nacional de Promoción General del Conocimiento. Ministerio de Ciencia y Tecnología (BSO2000-1196). 2001/03.

\section{Referencias bibliográficas}

Alonso, V. (1989). Glaciares rocosos fósiles en el área de Degaña-Leitariegos (Occidente de Asturias, Cordillera Cantábrica). Cuaternario y Geomorfología, 3: 9-15.

Alonso, V. y CORTE, E. (1992). Postglacial fracturing in the Cantabrian Cordillera (NW Spain). Zeischrift für Geomorphologie N.F., 36: 479-490.

ANDRÉ, M.F. (1992). Rock glaciers in central and north western Spitsbergen. Rev. Géom. Dynamique, 41 (2): 47-63.

BARSCH, D. (1977). Nature and importance of mass-wasting by rock glaciers in alpine permafrost environments. Earth Surface Processes, 2: 231-245.

BARSCH, D. (1987). The problem of ice-cored rock-glacier. In, J.R. Giardino, J.F. Shroder Jr. y J.D. Viteck (eds). Roc glaciers, Allen \& Unwin, London, 45-64.

BARsCH, D. (1992). Permafrost Creep and Rockglaciers. Permafrost and Periglacial Processes, 3: 175-188.

BARSCH, D. (1996). Rock glaciers. Indicators for the Present and Former Geoecology in High Mountain Environments. Springer, Berlin. 331 p.

BARSCH, D. y KING, L. (1975). An attempt to date fossil rock glaciers in grison, Swiss Alps. Quaest. Geogr., 2: 5-14.

Blagbrough, J.W. (1984). Fossil rock glaciers on Carrizo Mountain, Lincoln County, New Mexico. New Mex. Geol., 6: 65-68.

Blagbrough, J.W. y Farkas, s.e. (1968). Rock glaciers in the San Mateo Mountains, southcentral New Mexico. American Journal of Science, 266: 812-823. 
Borowicz, D., y ZuRAwEK, R. (2003). Topography of a composite relict rock glacier, Sleza Massif, SW Poland. Geografiska Annaler, 85A: 31-41.

Calkin, P.E., Haworth L.A. y Ellis, J.M. (1987). Rock glaciers of Central Brooks Range, Alaska, U.S.A. In, J.R. Giardino, J.F. Shroder y J.D. Vitek (eds.), Rock glaciers. Allen \& Unwin, London, 65-82.

CASTAÑÓN, J.C. (1986). Formas de relieve de origen nival y periglaciar en el borde noroccidental de la Sierra de Aramo. Ería, 10: 127-130.

Castañón, J.C. y Frochoso, M. (1994). El periglaciarismo de la Cordillera Cantábrica. En, A. Gómez Ortiz, M. Simón Torres y F. Salvador Franch (Eds.), Periglaciarismo en la Península Ibérica, Canarias y Baleares. Serv. Pub. Univ. Granada, P: 75-91.

ChuecA, J. (1989). Características de los glaciares rocosos del área meridional del batolito de Panticosa (Pirineo Oscense). Geographicalia, 26: 61-74.

DAwson, A.G. (1977). A fossil lobate rock glacier in Jura. Scott. J. Geol., 13: 37-42.

DíAz MARTínEZ, E. (1989). Notas sobre el glaciarismo y periglaciarismo cuaternario en la Sierra de Peña Labra (Cordillera Cantábrica). II Reunión del Cuaternario Ibérico (Madrid). AEQUA-GTPEQ, p: 8.

Dzierzek, J. y NityChoruk, J. (1986). Types of fossil rock glaciers in the Polish High Tatra Mountains. Bull. Pol. Sci. Earth, 34: 409-418.

Evin, M. (1985). Contribution à l'étude de la macrofissuration dans les parois situées à l'amont des glaciers rocheux des Alpes du Sud (France, Italie). Revue de Géomorphologie Dynamique, 34: 17-30.

Evin, M. (1988). Repartition, morphologie et structure interne des glaciers rocheux des Alpes du Sud en fonction de la lithologie et de la fracturation. Bull. Centre de Géomorphologie C.N.R.S., 34: 137-158.

EvIN, M. y FABRE, D. (1990). Distribution of permafrost in rock glaciers of the Southern Alps (France). Geomorphology, 3: 57-71.

FRAUENFELDER, R. y KÄÄB, A. (2000). Towards a paleoclimatic model of rock glacier formation in the Swiss Alps. Annals of Glaciology, 31: 281-286.

Frochoso, M. (1990). Geomorfología del valle del Nansa. Serv. Pub. Univ. de Cantabria, Santander.

García de Celis, A. (1991). Los glaciares rocosos de la Sierra del Suspirón (León). Polígonos, 1: 9-20.

García de Celis, A. (1997). El relieve de la Montaña Occidental de León. Univ. de Valladolid, Valladolid. 
Gómez OrTiz, A. y Pérez GonZÁLEz, A. (Eds.) (2001). Evolución reciente de la geomorfología española (1980-2000). Aportación Española a la V Conferencia Internacional de Geomorfología (Tokio, 2001). S.E.G y Univ. Barcelona. 427 p.

Gómez Ortiz, A.; Simón Torres, M. y Salvador Franch, F. (Eds.). 1998. Periglaciarismo en la Península Ibérica, Canarias y Baleares. Estudios significativos. Serv. Public. Univ. de Granada, 217 p.

GonzÁlez GutiéRrez, B. (2002). El relieve de los valles Torío y Curueño (Montaña Cantábrica Leonesa). Univ.de León, León.

GonzÁlez GutiérReZ, R.B., Redondo VeGA, J.M. y Gómez Villar, A. (2004): Rock glaciers in Gistredo Range, Cantabrian Mountains, Spain. Study of their morphomerical and morphodynamic parameters for a paleoambiental reconstruction during Late Quaternary. Third International QRA postgraduate Symposium, Brussels.

Gorbunov, A.P. (1983). Rock glaciers of the mountains of middle Asia. Proc. $4^{\text {th }}$ Int. Conf. on Permafrost, Fairbanks, Alaska. National Academic Press, Washington, p: 359-362.

HAEBERLI, W. (1985). Creep of mountain permafrost: internal structure and flow alpine rock glaciers. Mitteilungen der Versuchsanstalt für Wasserbau, Hydrologie und Glaziologie, 77: $1-142$

HumLum, O. (1982). Rock glacier types on Disko, central West Green-land. Geografisk Tidsskrift, 82: 59-66.

HumLum, O. (2000). The Geomorphic Significance of Rock Glaciers: estimates of rock glacier debris volumes and headwall recession rates in W Greenland. Geomorphology, 35: 41-67.

Ikeda, A. y MatsuoKa, N. (2002). Degradation of Talus-derived Rock Glaciers in the Upper Engadin, Swiss Alps. Permafrost and Periglacial Processes, 13: 145-161.

JíMENEZ, M. (1996). El glaciarismo en la cuenca alta del río Nalón (NO de España): una propuesta de evolución de los sistemas glaciares cuaternarios en la Cordillera Cantábrica. Rev. Soc. Geol. España, 9 (3-4): 157-168.

JonG, M.G.G. y KwADIJK, J.K. (1988). Fossil rock glaciers in central Vorarlberg, Austria. Arct. Alp. Res., 20: 86-96.

Kotarba, A. (1988). Fósil rock glaciers in the Polish Tatra Mountains: origin and age. In, M. Pécsi \& L. Starkel (eds.), Paleogeography of Carpathian Regions. Geogr. Res. Inst. Hungarian Acad. Sci. Budapest, 161-169.

MATSUOKA, N. y IKEDA, A. (1998). Some observations regarding mountain permafrost in the Japanese Alps. Annual Report of the Institute of Geoscience. University of Tsukuba, 24: $19-25$. 
Nicholas, J.W. y Garcia, J.E. (1997). Origin of fósil rock glaciers, La Sal Mountains, Utah. Physical Geography, 18: 160-175.

Pérez Alberti, A., y Rodríguez, M.A. (1993a). Formas y depósitos de macroclastos y manifestaciones actuales de periglaciarismo en las sierras orientales de Galicia. En, A. Pérez Alberti, A. Guitian y P. Ramil (eds.), La evolución del paisaje en el entorno de los Caminos Jacobeos. Xunta de Galicia, Santiago de Compostela, 92-115.

Pérez Alberti, A., RodríGueZ, M.A., y VAlCÁRCel DíAZ. M. (1993b). Reconstrucción paleoambiental a partir de formas y depósitos superficiales en el límite galaico-asturleonés. $3^{a}$ Reunión del Cuaternario Ibérico, Coimbra.

Redondo Vega, J.M. (2002). El relieve glaciar de la Sierra de Gistredo. En, J.M. Redondo Vega, A. Gómez Villar, R.B. González Gutiérrez y P. Carrera Gómez (Coords.), El modelado de origen glaciar en las montañas leonesas. Univ. de León, León, p: 105-131.

Redondo Vega, J.Ma'., Gómez Villar, A., y González Gutiérrez, B. (1998). Los glaciares rocosos fósiles de la Sierra de Gistredo (Montaña Cantábrica), León. En, A. Gómez Ortiz y F. Salvador Franch (eds.), Investigaciones recientes de la Geomorfología Española. Aportaciones a la V Reunión Nacional de Geomorfología, Granada, 745-750.

Redondo Vega, J.Mª, Gómez Villar, A., González Gutiérrez, B., y CARrera Gómez, P. (2002a). Caracterización de los macizos que dominan los glaciares rocosos fósiles de la Sierra de Gistredo (León): Influencia de la fracturación en la génesis y desarrollo de esas formas periglaciares. En, E. Serrano y A. García de Celis (eds.). Periglaciarismo en montaña y altas altitudes, V Reunión IPA-España, Univ. de Valladolid, Valladolid, 27-36

Redondo Vega, J.Mª Gómez Villar, A., GonzÁlez Gutiérrez, B., y Carrera Gómez, P. (2002b). Los glaciares rocosos fósiles de la Sierra de Gistredo (Montaña Cantábrica): datos preliminares para la determinación de su fábrica. En, A., Pérez-González, J. Vegas y M.J. Machado (eds.). Aportaciones a la Geomorfología en España en el inicio del III Milenio. Actas de la VI Reunión Nacional de Geomorfología, Madrid, 551-556.

RodríGueZ FernándeZ, L.R. (Dir.) (1982a). Mapa Geológico de España, E. 1/50.000. Villablino (101). IGME, Madrid.

RodríGueZ Fernández, L.R. (Dir.) (1982b). Mapa Geológico de España, E. 1/50.000. Noceda (127). IGME, Madrid.

RodríGUEZ FERnÁNDEZ, L.R. y HEREDIA, N. (Dirs.) (1994). Mapa geológico de la provincia de León. ITGE y Diputación de León. Madrid.

Schoeneich, P. (1992). Glaciers rocheux fossils dans les Préalps vaudoises. Bull. Soc. Vaudoise Sci. Nat, 82: 35-55.

SERET, G. (1983). The origin and movement of rock glaciers. In, E.B. Evenson, C. Schluchter \& J. Rabassa (eds.), Tills and related deposits. Elsevier, Rotterdam, 93-100. 
Serrano, E. y Agudo, C. (1998). Glaciares rocosos activos de los Pirineos. En, A. Gómez Ortiz, F. Salvador Franch, L. Schulte \& A. García Navarro (eds.), Procesos biofísicos actuales en medios fríos. Estudios recientes. Barcelona: Public. Universitat de Barcelona, 133-154.

Sissons, J.B. (1976). A fossil rock glacier in Wester Ross. Scottish Journal of Geology, 11: 83-86.

SLOAN, V.F. y DYKe, L.D. (1998). Decadal and millennial velocities of rock glaciers, Selwyn Mountains, Canada. Geografiska Annaler, 80A (3-4): 237-249.

VALCÁRCEl DíAZ, M. (1998). Evolución geomorfológica y dinámica de las vertientes en el noroeste de Galicia. Tesis Doctoral. Dpto de Xeografíia. Universidade de Santiago. $420 \mathrm{p}$.

Wahrhafting, C. y Cox, A. (1959). Rocks glaciers in Alaska Range. Geol. Soc. Am. Bull., 70: 383-436.

Whalley, W.B. (1976). A fossil rock glacier in Wester Ross. Scottish Journal of Geology, 12: $175-179$.

WHITE, P.G. (1979). Rock glacier morphometry, San Juan Mountains, Colorado. Geological Society of American Bulletin, 90: 515-518.

WILSON, P. (1990). Morphology and sedimentological characteristics and origin of a fossil rock glacier on Muckish Mountain, northwest Ireland. Geographiska Annaler, 72A: 237247.

ZIELINSKI, G.A. (1989). Lacustrine sediment evidence opposing Holocene rock glacier activity in the Temple Lake Valley, Wind River Range, Wyoming, U.S.A. Artic Alpine Research, 21: 22-33. 